\title{
A Field Guide for the Review Process: Writing and Responding to Peer Reviews
}

\author{
(Tutorial for Journal of Consumer Research)
}

\author{
RAJESH BAGCHI \\ LAUREN BLOCK \\ REBECCA HAMILTON
}

JULIE L. OZANNE*

*All four coauthors contributed equally to this manuscript. We would like to thank our colleagues for reading drafts of this tutorial and providing very helpful suggestions: Samuelson Appau, Sara Baskentli, Simon Blanchard, Stacey Finkelstein, Elise Chandon Ince, Pragya Mathur, Lauren Mayor, Rebecca Rabino, and Daniel Villanova. 


\section{A Field Guide for the Review Process: Writing and Responding to Peer Reviews}

Field notes: observing academic. Setting: university office. Time: early evening

The researcher has had a busy day of teaching and research meetings and is now sitting down at her desk to catch up on what looks like a lot of emails. One of the emails is an invitation to review for a journal to which the researcher recently submitted a paper. She exclaims: "Reading this paper and writing a thorough review will take a full day and I hardly have even a moment to think!” She is now sitting quietly and appears to be ruminating on whether or not to do the review.

Field notes: observing academic. Setting: home office. Time: late morning

The researcher is online again and checking the status of a manuscript at the journal's website. This repetitive activity has spanned weeks and seems to be increasing - it is the sixth time in one day that the status has been checked. What role does this ritual play in the life of an academic? It is clearly a source of distress. Suddenly, the researcher cries out-is it the sound of anguish or relief? He is reading a letter from the editor [grimacing], followed by a hurried scanning of twelve pages of comments from an associate editor and three reviewers. He appears to be agitated, saying: “A risky revision-what does that mean? All of the reviewers are mentioning different concerns. Do I really have to do everything the editors and reviewers are asking?”

The peer review process—-both writing reviews for academic journals and responding to reviews of your own work-is fundamental to building scientific knowledge. This is the best system we have for selecting high quality research to publish, yet it is often misunderstood. What are the incentives for researchers to write high quality reviews when they are invited to participate in the review process? Is the best review the one that is most critical? As an author, how should you make sense of and respond to the lengthy and sometimes conflicting reviews you receive?

In this essay, we explain why you should invest time reviewing, how to write a constructive review, and how to respond effectively to reviews of your own work. Many journals provide instructions for reviewers (e.g., http://www.ejcr.org/instr-revs.htm) and other helpful 
essays exist (Kohli 2011; Shugan 2007; Sternberg 2006; Summers 2001; Varadarajan 1996). Our aim is not to duplicate these guidelines. Instead, we offer an insider's field guide based on our own experiences working within the review process as authors, reviewers, and associate editors. We hope that this field guide provides answers to $\mathrm{PhD}$ students who are just beginning their journeys, assistance to junior professors who are still figuring out their journeys, and reminders to seasoned scholars who often forget how long and winding the journey can be.

\section{A Worthy Destination-Why Review?}

We all know that submitting papers to peer-reviewed journals carries with it a reciprocal obligation to review for these journals, but is reciprocity the only incentive to review? Far from it. Reviewing allows researchers to stay up to date on cutting-edge research and new methods, develop their ability to take the perspective of the reviewer when submitting and revising their own work, build a network within the field, and develop important skills.

Stay Current. Reviewing papers gives you early access to still-developing theories and methods within the field. You get to read manuscripts that editors believe are within your domain of expertise. You become part of the conversation when standards shift, controversies arise, and new areas of research are deemed worthy.

Get an Insider's Perspective. Writing reviews helps you develop the perspective of a reviewer, thereby enhancing your ability to shepherd your own work through the review process. When you participate in the review process, you usually see not only your own review, but also the other reviews, the associate editor's report, and the editor's decision letter. Evaluating research as a reviewer helps you become attuned to "hearing” what reviewers and editors are actually saying. When you read reviews of your own work this experience will help you respond more effectively. 
Build your Network. Reviewing gives you a chance to work with well-connected editors and associate editors who will read your reviews very carefully. At many journals, you will not know the identity of the associate editors, but they will know yours. High quality reviews influence these editors and can build your esteem within the field. This is reputation building in quite a literal sense: at most journals, your reviews are rated by the editors and these cumulative ratings determine whether you are invited to be part of the editorial review board for the journal.

Develop your Mentoring Skills. Reviewing is a good opportunity to build mentoring skills. In doctoral programs, students are taught to critique research but generally get less practice being constructive. Being constructive involves identifying and developing the potential in ideas. In recent years, around 30\% of all papers published in JCR emerged from dissertation work, so reviewing is a crucial opportunity to help junior scholars publish their first work. You are mentoring the next generation of researchers.

\section{How to Write a Constructive Review}

\section{Preparing for the Journey}

So, you have decided that reviewing will help you and the profession. Now what? Do you wait around hoping that an editor will email you a manuscript? This strategy is likely to be as successful as drinking lattes at a café on Sunset Boulevard waiting to be discovered by a famous producer. It may work for some but is likely to be a risky strategy for most.

Early in your career, consider specializing in a couple of journals as an efficient way to get noticed. This means that you should regularly read articles published in your target journals as well as submit your own research. If you can publish in a journal, editors will begin thinking of you as someone who is qualified to review for the journal. If you have successfully published 
in a journal and you have not yet received an invitation to review, feel free to let the editor know you would be happy to serve as an ad hoc reviewer for the journal. Even stars have to pound the pavement sometimes before being discovered.

However, if you have not yet published in your target journals, it is unlikely that editors will reach out to you. You may still be able to review by serving as a trainee reviewer. For example, by participating in JCR's Trainee Reviewer program, you can partner with an experienced reviewer and shadow an actual review process. This provides a safe way to explore the terrain of reviewing. You can travel from reading the submission and writing your own review to reading the reviews of seasoned reviewers and the editors' final decision. To do this, find a colleague who publishes in JCR and ask this colleague to mentor you through the trainee process. As a trainee, your review will not be an official part of the process. But if you do a good job, then an editor may indeed “discover” you and send you a manuscript to review.

Okay, let's return to the opening scene. Imagine that you are the researcher being described, and an editor has emailed you an invitation to review a manuscript. Should you accept? Before you do so, look at the title (and abstract if one is provided). If the topic is completely outside your expertise-perhaps intended for that other researcher in the field with the same last name and first initial — tell the editor and politely clarify your areas of competency. However, if the topic is somewhat related to your work, consider it a good opportunity to update and expand your expertise. Keep in mind that even if the manuscript might initially seem outside of your area, often the editor has selected you for a reason, perhaps for your methodological expertise or because the editor was seeking a generalist and not an expert in order to balance out a team of reviewers. Second, if you read the title and immediately recognize that this is the work of your best friend from your doctoral program (or your advisor, or a colleague at your current 
institution, or better yet, someone you just love to hate), you have a conflict of interest. This is another reason to decline the review. Simply recognizing the work from a conference presentation may or may not present a conflict of interest; use your judgment to decide whether you will be able to provide an impartial review, and feel free to check in with the editor if you are in doubt. Or, if you read the title and recognize the manuscript as one you have already reviewed for another journal, let the editors know your history with the manuscript. In some cases, they may decide to assign the paper to another reviewer, but in others, they will ask you to proceed with the review. Finally, consider whether you can meet the deadline. It is indeed worth juggling your schedule to meet the deadline, but this may not always be possible: if you and your partner are expecting a baby at any moment, this is a good reason to opt out! You do not want to slow down the review process by being late with your report-this is not a great way to get noticed by editors.

\section{Charting Your Path}

So you have caught the eye of an editor, the manuscript before you is in your wheelhouse, and you have agreed to write a review. Now what? Your goal should be to write a constructive, high quality review. Constructive, high quality reviews do two things: they help editors decide whether the work is a good fit for the journal and they help authors improve their research. Too often, researchers view the peer review process as a way to keep bad research out of the journals and they assume that good reviews are highly critical. But the review process is at its best when it stewards research with potential towards publication. Reviewing allows you to advocate for early stage research if you believe its potential contribution is high and the authors can address important issues currently limiting its contribution. Constructive reviews also help authors improve their research. Whether you believe the work is a good fit for the journal or not, 
you can help improve the research even if it is eventually published at another journal.

Remember that the authors have probably spent upwards of a year, maybe even several years, working on this manuscript. In some cases, it will be their dissertation work or the first time they submitted a paper for review. Even more senior authors are likely to be more receptive to constructive reviews.

Learn the Terrain. Relax and read the paper with an open mind. Enjoy learning about someone else's research in detail. Start this journey early, at least several days before the review is due. Reading the manuscript early will help you estimate and schedule enough time to complete the review by the deadline. Read through the manuscript carefully, noting any questions and making comments. Pay attention to what the author is doing well and what could be done better.

By starting early, you have time to review any key articles upon which the author builds his or her argument. You do not need to undertake a detailed literature review, but do inform yourself about the current state of research in this area so that you understand the contribution this paper could potentially make. Also, note any key articles overlooked by the author or that could help position the contribution of the study.

Good reviewers try to step back as they are reading the paper to assess the overall value of the research. Challenge yourself to answer some general questions about the paper: "Was this an interesting paper?” "Did I learn something new?" “Are these findings important?” Was the study original?” “Was I convinced?” “What would I need to be convinced?” “So what?” Several researchers have written articles on this topic, and we recommend gathering a variety of perspectives (Ballinger and Johnson 2015; Davis 1971; MacInnis 2003; Stewart 2002). 
Separating the Forest from the Trees. Some reviews are a hurried list of problems presented in no particular order. These are disappointing reviews for both editors and authors to receive and try to follow. These reviews leave the author lost in a forest with little sense of whether to go north or south, east or west. More constructive reviews help the author chart a clear path. These reviews are like treasure maps. It takes tremendous clarity of thought for a reviewer to map a way forward to the potential treasure buried in a manuscript. Remember, though, multiple routes often exist to find the same buried treasure. Even if you have charted out what seems like a clear path, it is the authors' paper, and they may have a better sense than the reviewers of the obstacles on their island. As long as they address the key concerns, the authors may choose to follow a different path in revising the paper.

What are the landmarks on this path to the treasure? For instance, consider empirical research. All empirical research studies are made up of a problem (i.e., the substantive domain), an explanation (i.e., the conceptual domain), and the method and findings (the methodological domain and evidence). Some authors, editors, and reviewers may give more weight to one of these than to the others. But each is important and, when empirical research is done well, the pieces should fit together seamlessly. Think of that moment when the treasure hunters find the "X” that marks the spot: an important problem is tackled by providing a clear explanation and well-grounded empirical support.

To see why the substantive domain is important, imagine that the authors have designed a perfect study — the best ever done. As a reviewer, you must judge whether the author is tackling an important question, whether this question is a theoretical or a practical one. For more about judging contribution, we refer you to a recent tutorial on this topic (Janiszewski et al. 2016). Different types of papers are judged by different standards (see Lynch, Alba, Krishna, Morwitz, 
and Gurhan-Canli 2012; Sternberg 2006). Clearly, the substantive domain —-the importance of the problem—-must be judged against the backdrop of what has been done before. The author's job is to convince the reader by building their case and referring to existing literature on the topic. Some substantive contributions are nice extensions that flow directly from existing work. But, because a lot of work already exists, the evidentiary standards tend to be higher. Other times, the substantive contribution is more novel. In this case, the standards may be different because the author is at the frontier. More leeway is usually given.

The conceptual domain is also important. Here, the author provides the explanation, the process, the how, or the inner workings. Some people believe that theory is the anchor of any good study. When we understand how things work, then we may be able to generalize this explanation to other contexts. Most of the time, conceptual work involves refinements of existing theories. Again, if the research is building on a body of existing work then the standards may be high. But, if someone is proposing a novel extension of a theory or even a new theory, this is a harder task and the standards can be loosened a bit.

Finally, a good study is methodologically sound. Some experts will read the method section of a paper first, reasoning that if the empirical tests are done poorly, they will not care either about which question was asked or which theory was tested. It is in this domain that the reviewer is really trying to follow the trail of evidence. The author is staking out a problem and providing an explanation; does the evidence support the proposed explanation? Good empirical research seamlessly combines all three of these elements.

\section{Following the Path}


There are three parts to a review: 1) your report for the authors, 2) your overall recommendation to the editor, and 3) your confidential assessment to the editor. The fourth step, after drafting the three parts of your review, is submission. We discuss each in turn.

Step 1: Report for the Authors. The heart of your review is your report to the authors, which is generally between two and four pages long. Start with a brief summary to show that you understand the gist of the paper. It also helps the associate editor and editor understand your perspective and signals to the authors that you actually read the paper! Next, discuss the major strengths and weaknesses of the paper. Does the manuscript make an important contribution to theory or to our understanding of a substantive domain, and if not, why not? For example, if you feel that other authors have already established these findings, refer the authors to specific articles. If you believe the theorizing breaks down, explain how and show where? If you feel the methods being used are inappropriate, which methods should the authors use instead and why are these superior? Be specific and concrete.

Rather than creating a laundry list of problems, focus on the major issues and prioritize your concerns. In table 1, we provide some suggestions about what might qualify as an important concern within an experimental approach, which is often published in JCR. However, many methodological approaches exist; clearly no single approach will fit every manuscript. Constructive reviewing requires judgment and careful thought about what the authors are trying to accomplish. Also, remember that your task as a reviewer does not end with finding problems. A constructive reviewer also makes suggestions for improving a paper. Concrete suggestions are often most helpful, but try to remain open. Eventually, you may see a revised version of this manuscript. As the authors incorporate the entire review team's suggestions, they may take a different, yet reasonable, path to rewriting the manuscript. 
Step 2: Recommendation to the Editors: When you submit your review, you will be asked to make a recommendation to the editors about whether the paper should move forward in the review process. In addition to reading your review and the paper very carefully, the editors use your recommendation to inform their decision on the final disposition of the paper. These recommendations are not votes, but they are an important form of communication between the reviewers and editors. Although the author report and the recommendation to the editor are separate forms of communications, they should align. Making glowing comments to the authors but a negative recommendation to the editors leaves the editors in a tough position: they may be forced to make a negative decision about a manuscript without being able to point to any negative signals in the reviewer reports. The authors will also be very confused and even angry when the paper gets rejected.

When deliberating about your recommendation, consider both the potential contribution of the paper and whether it is likely that the authors can address important issues in one round of revisions. If the authors are proposing something interesting but have not developed a strong enough evidentiary trail (i.e., shown the process or provided enough empirical support), then you might recommend to the editors that they "Invite Revision.” Making this recommendation is a strong signal that you believe this paper can eventually be published. This means there is a clear path to revision (i.e., you can specify exactly what needs to be done to satisfy you). Offer a “Risky Revision” when the project shows promise but the way forward is unclear. If you don't believe the authors can address the issues you have raised, and these issues are critical to the contribution, then it is appropriate to recommend "Rejection.”

Step 3: Your Note to the Editors: Although it is not required, it is a good idea to summarize your opinion in a brief note to the editors. The editors read your comments to the 
authors very carefully, so there is no need to reiterate your review; rather, this is an opportunity to provide additional information that helps the editor make the final decision. Indicate how strongly you feel about your recommendation and explain why you feel this way. These comments will not be seen by the authors, so this is an opportunity to give candid and direct feedback to the editors. It is also an opportunity for you to indicate whether you have concerns about your own ability to evaluate portions of the paper. For example, if your training allows you to evaluate an experiment conducted by the authors but not an analytical model, note this in your comment to the editors. All researchers have areas within and outside their area of specialization. As editors balance differing evaluations across reviewers such disclosures are appreciated and signal academic maturity.

Step 4: Finalizing and Submitting the Review: Consider writing the review and setting it aside for a day. What sounds reasonable at the end of a long day can sound harsh and unkind in the morning's light. A sloppily edited manuscript may have gotten your ire: "You really need to get someone who is a native English speaker to read this!” Upon reflection, it is kinder and less biased to say: “Clear writing helps readers appreciate your contribution. This manuscript would benefit from a thorough editing by a professional copy editor.” Similarly, in your frustration, you might have written something like: “This has already been done.” With a little distance, you might say something like: "Please see Jones (2015) and Smith (2016) who have already published these findings.” Do not use the cover of anonymity to write an unkind review. In fact, it may be a good idea to write your review as if you are signing your name at the bottom. The recent PLOS ONE journal controversy is a cautionary tale: the cloak of anonymity provides no cover if reviewers behave badly, such as making blatantly sexist comments in a review (Bernstein 2015). 


\section{Traveling the Path Once Again}

If the editors invite the authors to revise their paper, it usually goes back to the same reviewers and associate editor who evaluated the initial submission. When you review a revision, the steps are similar to those followed for an initial submission except that you have a shared history: the path forward that was charted by the editor and associate editor based on the previous round of reviews.

After you have had a chance to read the revised submission, read the previous set of reviews and the authors' responses to these reviews. It is okay to focus more on your own review and the authors' responses to you. Clearly, we all have a unique perspective. But it is also important to understand how your comments fit into the editor's or associate editor's bigger map. If the associate editor emphasized your concerns in his or her report to the authors, you should expect to see these concerns addressed by the authors in their revised submission. However, if the editorial team gave the authors clearance to follow a different path, then be gracious and back off your demands unless you feel that they are truly critical (and, if this is the case, be sure to explain why they are critical in your comments to the editors). Remember, one reason to do reviews is to learn from more seasoned and experienced scholars. Hard as it may be to believe, you could just be wrong.

When evaluating a revision, try to be fair to the authors by not bringing up new concerns about theory and empirical evidence that you failed to raise in your previous review. Otherwise, you are setting a moving target for the authors, and imagine how you would feel about this as an author! If you feel you missed something critical in a previous round, explain this to both the authors and the editors in a way that allows the editors to adjudicate fairly. However, if the authors have significantly revised their theory or methods in the new submission, or collected 
new data, these changes should be evaluated carefully, much like you would evaluate them in a new submission.

It is important to remember that science is an iterative process. Our goal as reviewers is to improve-rather than perfect—research. Ideally, reviewers find a balance: each review cycle may improve a paper, but it also imposes costs on the authors, reviewers, and editors, and delays dissemination of knowledge. A constructive reviewer assesses the importance of resolving each concern before moving forward in the review process and communicates this to the editors.

At the beginning of this article, we suggested that writing reviews could help you improve your skills as an author and help you respond more effectively to reviewers. Now, as promised, we'll flip the conversation and discuss some strategies for authors responding to reviewers.

\section{How to Respond Effectively to Reviewers}

\section{Don't Bury Your Treasure}

So far, we’ve been talking about how reviewers can make the review process more constructive, but authors also play a critical role. Writing and responding to reviews are two sides of the same conversation. Based on our experience, this conversation is more productive when authors have invested their best effort in preparing their paper for review, when they are open to improving their work, and when they respond to the spirit as well as the specifics of the reviews. So, before you start the review process, assess whether your paper is ready for submission.

By the time reviews of your paper come back to you, careful reviewers have invested at least one full day, and often more, reading your paper and writing their reviews. The associate editor and editor have taken the time to read both your paper and the reviews. This brings the 
total to between four and six person-days invested! You really have one initial shot to make a good impression and turn reviewers into supporters.

So, sweat the details. Grammatical errors and failure to cite relevant literature are not only distracting, they communicate that the author hasn’t attended to detail. It is hard to avoid making attributions, such as that sloppy writing may mean sloppy research. Have you doublechecked all of the statistical tests? Have you provided enough methodological detail for reviewers to feel confident in your procedures? At a higher level, pay attention to important guideposts, such as whether the title and headings clearly communicate the macro structure of the paper. Do you have clear lead sentences in paragraphs that build a linear narrative? Reviewers are much more likely to see potential and provide helpful feedback when authors have prepared their paper well.

Finally, be sure your paper is ready for the review process by asking colleagues to read your paper and give you a friendly review before submitting it for the first time. Asking them to tell you "what they think reviewers might criticize" will encourage them to provide helpful suggestions without making them feel uncomfortable about critiquing your work. Follow their advice to address issues as well as possible, carefully read it over again and then submit your paper.

\section{A Few More Miles to Go? Or Do You Need a New Map?}

Fast forward to the time when you have already waited for weeks, expecting news. Then one fine day you open your inbox and see an email that says "Final Decision” in the subject line. “Oh NO!” This is the moment of truth. It takes a lot of courage to click on this email. We know! Believe us when we say that some things never change-even after many years of receiving such emails, we all still feel anxious too. Take a deep breath and click on the email. 
You skim through the editor's letter and the first paragraph reads like a form letter. At least this is how your brain interprets it. All you really want to know is: was my paper rejected or did I get a revision? Finally, you come across the line that says "I am offering you a revision opportunity.” Really? Congratulations! You have been invited to submit a revision. You are on track - the reviewers see the value in your buried treasure and will help you uncover it. You only have a few more miles to go. Time to celebrate. Run down the hall and find a colleague.

“Hoorah, a revision!” This is a special occasion indeed! Enjoy the moment, daydream about your first (or your next) JCR. Do not spoil the moment by reading the reviews too carefully now. You will have ample opportunity to do this tomorrow and in the coming weeks and months.

\section{Check Your Navigational Coordinates to Get Back on Track}

Relax and read the reviews with an open mind. Remember, as we discussed earlier, the review process works best when both reviewers and authors begin with an open stance toward improving the work. It is easy to forget this when we initially receive a set of reviews. Often, our first reaction as an author reading the reviews is to deny the value of the comments or possibly even the reviewer (“This reviewer did not get my paper at all!”). This is then followed by the other familiar stages of grieving: anger ("I put so much effort into that study, I am not going to cut it.”) and sadness (“I don’t have the energy to think about this now.”). However, the key to a successful review process is to move beyond these debilitating feelings to the facilitating stage of acceptance, when you can begin to more clearly see the problems with your own work and acknowledge that many of the reviewers' suggestions would indeed improve the quality or clarity of your work.

So, our recommendation is to read the reviews and then put them down for a few days so you can process the content more dispassionately. Regardless of whether your paper has been 
rejected or you have been offered the opportunity to revise, accepting and acknowledging the core issues raised by the review team will almost certainly improve the quality of your paper. While investing considerable time and energy in our research, we become attached to our papers, our theories, and our methods. In this context, suggestions for improvement can feel like personal attacks. Before mobilizing your defenses, though, take a step back and try to see your work from the reviewers' perspective. The review process is not a series of attacks to be defended, but a process through which research usually becomes better.

Own the Criticisms. If the reviewers missed something in the paper, or didn't understand something you thought you explained, recognize that this means that you didn't communicate it clearly or sufficiently. If the reviewers don't accept your conclusions, then your evidence wasn’t strong enough. Owning your mistakes rather than defending your position is a critical skill to develop.

"Be" the Reviewer. If this manuscript was sent to you for a blind review, would you likely come up with similar concerns? Considering the comments from the reviewers’ perspectives may help you better interpret their meanings.

Constructive reviewers may try to be tactful, using phrases such as, “I don’t understand...” or “It wasn’t clear to me...” Effective responses understand that these reviewers aren’t slow, they are simply trying to be tactful. Authors who interpret comments like these broadly_as a call for clarity rather than as one person's confusion—-tend to navigate the review process more successfully.

Own the Solution. Keep in mind that reviewing is a volunteer task and the reviewer has invested 1-2 days to provide you with comments. That's a lot of generous time, but it's still a small amount of time compared to how long you have spent working on your research. 
Reviewers are merely providing suggestions. So recognize that while they may suggest a solution to a particular problem, it is your job as the author to understand the core issues being raised and determine the best solution. You can, and probably should, do something different if you have a better (and not just an easier) way of addressing the core problem, and you can explain why you have taken a different approach in your response to the reviewer. Use the associate editor's report to keep your focus on the core issues. We find that some authors dot all the i's and cross all the t's on the small stuff but miss the big picture concerns. Sometimes reviewers offer conflicting advice. If the associate editor highlights Reviewer A's point but says nothing about Reviewer B's conflicting point, this is a tactful way to signal you to pay attention to $\mathrm{A}$ and not $\mathrm{B}$.

Check the Compass! It is important for you to understand what the critical concerns are before starting work on your revision. Fortunately, the associate editor's report provides guidance on what you should do. Remember, at $J C R$, it is the associate editor and the editor you have to please. However, the associate editor and the editor's decisions and recommendations will be based on what the reviewers say. So, use the associate editor's report as a guide for prioritizing the concerns, but it is also important to go through each reviewer's comments very carefully. The associate editor's report will not mention every minor comment that came up in the individual reviewer's reports, but this is because the associate editor is focusing on the big picture. Think of the minor comments as low hanging fruit: compared with the major concerns, fixing them will be easy, and doing so will both improve the paper and demonstrate that you are heeding the entire review team's advice.

Have a Good Conversation. Think of the reviewers' comments as the beginning of a conversation that you get to have with three smart, experienced peers. If the editor has offered a 
revision opportunity, now you have the chance to keep the conversation alive. Be respectful and gracious but not obsequious. The right tone should convey your appreciation for their time and ideas, but not drip with insincere flattery.

The golden rules of conversation apply. Be a good listener. Avoid unnecessary details. Don’t contradict, especially if it's unimportant. Don’t always be the hero of your story. Do not exaggerate. Do not misquote. Cultivate tact.

\section{Writing Comments to Reviewers}

There is no "best" or "right” way to structure your written responses, other than to say that the right way is the one that most respectfully and efficiently honors the reviewers' time. Beginning with an overall summary that applies to the entire review team is usually helpful. Then you can respond individually to points not otherwise covered in the overall summary; in other words, avoid verbosity and redundancy. Help the reviewer understand your response by gently reminding her what she asked of you and why. This does not mean you need to cut and paste original comments in a Q\&A fashion. Rather, you could summarize the issue: "To further enhance our potential contribution, you asked us to relate our work to the early works of Hemingway and Faulkner.” Or you might embed the issue in your answer: "Our two new studies rule out your primary concern with our manuscript — that our results might be open to the alternative explanations of political and religious beliefs.” It is always helpful to point the reviewer to the specific place in the revised document that addresses their concern: "As you requested, we now discuss the impact of our work for managers and regulators—see General Discussion.”

In the end, although the reviewers’ suggestions are just that-suggestions-remember that the reviewers each took a day and often more out of their lives to help you improve your 
research. Ignoring their suggestions without explaining why you haven't addressed them is not only impolite, it’s also likely to make them less receptive when they evaluate your revision. A good piece of advice is to follow the associate editor's and editor's reports, which are a roadmap for your revision. This means that you may not have to follow all of the reviewers' suggestions in a literal manner, but you can instead address the spirit of their concerns. Be sure to explicitly explain your approach in your response so that the reviewers know they have been heard; for example, "We followed the associate editor’s advice to test the boundary conditions of our theory, which allows us to address your concern in an alternate way.”

If you received a "Risky Revision,” then your path forward is less clear. The review and editorial team has not provided you with a map. You will likely need to work far harder and very carefully to come up with your own map to unearth the treasure you believe remains. This is where the "going gets tough and the tough get going!" You may need to collect additional data to untangle issues raised by the review process. You may need to return to the literature to read more deeply to better advance your thesis. And, at times, the problems may seem insurmountable. We have found that taking a break from the project can sometimes provide the critical distance needed to see a clear way forward. Similarly, a fresh perspective of a more experienced colleague may help. If you do resubmit your manuscript, be sure to communicate this new map in your responses to the review team as well as in the structure of your revised paper. Remember, however, that you were offered a risky revision—which means the reviewers found some promise in your ideas. It is, therefore, your responsibility to convince them of your contribution and provide them with a strong evidentiary trail.

Many manuscripts get rejected (we know, we’ve been there, too). We suggest taking a little time to absorb the critique and then trying to address the review team's concerns. As 
tempting as it may be to submit the paper just as it is to another journal, hoping for more sympathetic reviewers, we strongly advise against this approach. One reason is that you may get one or more of the same reviewers at another journal, and their reaction to an unchanged paper is highly unlikely to improve. A second, even more important reason is that you have just received valuable feedback from the review team. Minor concerns will be easy to address and you can eliminate these distractions. More major concerns - such as those about the manuscript's contribution - will be more challenging to address, but good reviewers will have pointed you to other relevant work, critical issues to consider, or limitations of your empirical evidence. Thinking carefully about how to address these issues, whether through better positioning or gathering new evidence, will probably help your chances at the next journal. The silver lining in the dark cloud of rejection is that in many cases, this extra review cycle will make the review process easier at the next journal.

\section{Enjoy the Journeys Ahead}

Our hope is that you will learn from the peer review process. We continue to do so every time we submit or review a paper. It is not a perfect system—-there will undoubtedly be differences of opinion and unpolished gems may be missed—but it is the best system we have for selecting high quality research to publish. This guide is an attempt to share with you the joy of the journey as well as some of the lessons learned along the way that can make you a more constructive reviewer and an author who more effectively advocates for your work. 
TABLE 1

Potential Questions and Ways to Assess Experimental Work

\begin{tabular}{|c|c|c|}
\hline & Questions & Ways to Assess \\
\hline 1 & Evaluating Contribution & Refer to the Tutorial by Janiszewski et al. 2016 \\
\hline $2 \mathrm{~A}$ & $\begin{array}{l}\text { Evaluating Theory } \\
\text { Are the authors building new theory } \\
\text { or applying existing theory? } \\
\text { Does the theoretical framework } \\
\text { make sense? } \\
\text { Is the theory discussed in sufficient } \\
\text { detail? Does accepting the theory } \\
\text { require logical leaps of faith, or are } \\
\text { all links conceptually supported by } \\
\text { the extant literature and logical? }\end{array}$ & $\begin{array}{l}\text { Create a representation of all the concepts or } \\
\text { constructs using a Nomological Network. A } \\
\text { Nomological Network allows you to look at all the } \\
\text { constructs and assess how they relate to each } \\
\text { other. } \\
\text { Use standard validity concepts_-such as face } \\
\text { validity, internal validity, convergent and } \\
\text { discriminant validity, and external validity. } \\
\text { - On the face of it, do the proposed } \\
\text { relationships make sense? Are they } \\
\text { believable? Are they consistent with } \\
\text { findings in the field? } \\
\text { - With respect to internal validity, do the } \\
\text { different components of the theory make } \\
\text { sense-do they seem to cohere together? } \\
\text { Are the proposed relationships consistent } \\
\text { with the theory? } \\
\text { With respect to convergent and } \\
\text { discriminant validity, are related constructs } \\
\text { related and unrelated constructs unrelated? } \\
\text { Regarding external validity, do the } \\
\text { constructs map to observable phenomena? }\end{array}$ \\
\hline 2B & $\begin{array}{l}\text { Evaluating Proposed Process } \\
\text { Do the authors propose an } \\
\text { underlying process (why their IV } \\
\text { impacts the DV)? } \\
\text { Does the underlying process make } \\
\text { sense? Is it succinct? Is it coherent? } \\
\text { Could there be other explanations? }\end{array}$ & $\begin{array}{l}\text { Again, you could use the approaches discussed } \\
\text { above to make your assessments. } \\
\text { Process should follow naturally from the theory } \\
\text { used. It should be succinct. } \\
\text { Are there alternative processes that may explain } \\
\text { the findings? Have the authors discussed them? }\end{array}$ \\
\hline 3A & $\begin{array}{l}\text { Evaluating Empirical Methodology. } \\
\text { Hypothesis testing } \\
\text { Do the studies test the hypotheses } \\
\text { proposed? Do the studies together }\end{array}$ & $\begin{array}{l}\text { Using the validity approaches suggested earlier } \\
\text { can help. That is, on the face of it, do the designs }\end{array}$ \\
\hline
\end{tabular}




\begin{tabular}{|c|c|c|}
\hline & $\begin{array}{l}\text { make the same general point? Are } \\
\text { the authors using the same or } \\
\text { different measures across these } \\
\text { studies? } \\
\text { Do the findings across studies } \\
\text { support or contradict each other? Is } \\
\text { the pattern of findings consistent } \\
\text { across studies? }\end{array}$ & $\begin{array}{l}\text { and variables used capture the actual constructs } \\
\text { being studied? With respect to internal validity, do } \\
\text { the different studies hang together tightly and } \\
\text { reinforce one another? Are the tested relationships } \\
\text { consistent with the hypotheses proposed? } \\
\text { Assessing reliability could also be helpful. Are the } \\
\text { findings replicating across the different studies? }\end{array}$ \\
\hline $3 B$ & $\begin{array}{l}\text { Process Testing } \\
\text { Do the studies test the appropriate } \\
\text { relationships among variables and } \\
\text { the proposed process? } \\
\text { Have the authors ruled out } \\
\text { alternative explanations? }\end{array}$ & $\begin{array}{l}\text { Do the studies establish causation if a causal } \\
\text { relationship is predicted, or merely correlation? } \\
\text { Are the mediating variables and dependent } \\
\text { variables measured in the same study? } \\
\text { Are variables measured and reported that allow the } \\
\text { authors to show that alternative processes do not } \\
\text { explain the effects? }\end{array}$ \\
\hline $3 C$ & $\begin{array}{l}\text { Individual Studies } \\
\text { Have each of the studies been } \\
\text { designed properly? } \\
\text { Are there measurement problems? } \\
\text { Have appropriate statistical } \\
\text { approaches been used? }\end{array}$ & $\begin{array}{l}\text { For instance, are the independent variables truly } \\
\text { orthogonal? Are there confounds? } \\
\text { For example, do measures suffer from common } \\
\text { method biases? } \\
\text { Are the authors making incorrect inferences? Have } \\
\text { they mean centered continuous variables, if is } \\
\text { appropriate to do so? Are they conducting the } \\
\text { correct mediation tests? } \\
\text { Have they reported all the details needed? } \\
\text { That is, are the authors able to demonstrate } \\
\text { external validity? If the stimuli is artificial, does } \\
\text { its artificiality help to avoid other problems? }\end{array}$ \\
\hline
\end{tabular}




\section{Frequently Asked Questions About Reviewing}

\section{What should I do if a paper I am asked to review is very similar to a project I am currently working on?}

Many of us read the same literature and use the same theories to build our work. It is inevitable, then, that this sometimes leads to independent authors working on similar questions in a similar manner. This is actually a good thing for science and knowledge creation. From our experience, what at first seems dangerously similar often feels more dissimilar once you have had a chance to get over the shock and worry about being scooped. Most often, there are enough distinctions between the two projects to enable both to go forward. As a reviewer, it is your obligation to review the paper as objectively as possible. Keep in mind the authors are likely unaware of your own work, as you were of theirs, and so it is not fair to judge them against what you may have found, nor should they be penalized for simply getting there first. Our advice is for you to reframe the negative into a positive and view this as a fortunate event; it gives you the opportunity to steer your work towards a more clear distinction and contribution before you submit it to a journal for review. Of course, if you feel emotionally unable to be a neutral and objective reviewer, communicate this to the editor and recuse yourself.

\section{What should I do if I know who the authors are?}

This is a tough one. Of course, the best case scenario is a double-blind review. It is naïve to think that this always happens. Sometimes you might know the identity of the authors because you have seen presentations of their preliminary work. In this instance, it is okay for you to review as long as you truly believe you can remain impartial and unbiased. However, there might be other situations in which it is best to immediately recuse yourself; for instance, if you work closely with the authors or if you provided feedback on earlier drafts. To help maintain integrity in the review process, we strongly encourage you to refrain from conducting an Internet search to identify the authors after you have agreed to review the manuscript.

\section{What is the best format to follow when reviewing a paper?}

Well, we think following the advice given in this field guide is a great place to start! Also read the reviewing guidelines posted on most journals' websites. There is no one best format, but the most helpful reviews provide a holistic summary as well as specific, pointed concerns. Many people find it helpful to write a first draft that simply gets their thoughts on paper as they follow the article through. Resist the urge to submit this draft immediately just to cross it off your to-do list. Perhaps come back to it after a day or two and re-organize the comments in a way that best assists the authors. This strategy also gives you the opportunity to rephrase what may have been initial venting into more constructive comments. 
What should I do if I don't have time to review a paper? Will refusing to review a paper be bad for me? Are there any negative consequences to saying no?

As a junior reviewer, it is always a good idea to make the time to do the review. Unless there is a conflict of interest, refusing to review is generally ill-advised. While there won't be any immediate consequences, declining a review is noted in the system and, at least for some journals, the associate editors and editors have access to that information. Repeatedly refusing to review is likely to keep you off editorial boards. If you know in advance that you will be out of commission for an extended period of time, notify the managing editor and you can be marked as temporarily unavailable.

\section{What should I do if I am sent a paper that is outside of my area of expertise? How should I review it? Should I review it?}

The editors of journals try to pick a team of reviewers who together provide the necessary expertise. So, it might be the case that you are not that familiar with the content area, but you bring expertise in the methodology, or vice versa. Try to read up a bit on the area you are not familiar with, but focus the review on what you know. It is okay to acknowledge to the authors that this isn't your area of expertise. You should certainly let the editors know in your private communication to them. However, if you feel that you have no understanding of the area at all and do not believe that you will be able to do justice to the paper then it might be reasonable to recuse yourself.

\section{Should reviewer feedback about the theory of a paper only rely on existing research or might intuitions also help? As a Ph.D. student, I have read published papers suggesting results counter to what I would expect. I wonder whether giving feedback only based on existing research might also have drawbacks (e.g., narrowing your perspective).}

Your task as a reviewer is to bring objectivity to the table. Do the authors empirically support their theorizing? Is their theorizing solidly built on a foundation of existing literature? If so, this is a justifiable starting point. We rely on existing research because published research has been vetted by experts; it has undergone a rigorous review process. These published findings are reproducible and generalizable, thus making them valuable for assessing the contribution of the current work.

That said, science is a pursuit undertaken to understand the world. Do the authors propose relationships that do not reflect what you observe in the real world? If so, you might point out issues with external validity. Another approach could be to suggest that the authors consider when the opposite results might hold; this approach is most helpful if you can provide the authors with some suggestions for moderators or individual differences that might provide results in line with your intuition. We caution, though, that reviewers should not expect authors to test their "potentially interesting” intuitions; instead, reviewers should consider conducting their own research to test their hunches and allow the authors to write their paper based on sound justification from previous research. 
How do you determine if a paper has made a 'sufficient' contribution? What factors often do go into that decision, and what ought to?

To avoid duplication, we suggest that you refer to a valuable tutorial written by Janiszewski et al. (2016) on how to judge contribution.

If, as a reviewer, you find the paper/theory/effects are straightforward or even obvious, how should that affect your evaluation?

You will need to make that judgment based on the journal for which you are reviewing. If it is for $J C R$, then the contribution will be a very important factor. However, the mere simplicity of the theory does not necessarily limit the contribution of a paper. Sometimes, even when the theory is straightforward, the findings can be important and novel. However, there may be occasions when both the theory and findings appear somewhat straightforward. For example, existing theory in another discipline may be applied to a problem in the journal's domain. In this case, if the theoretical advance is limited, you can evaluate the importance of the practical implications.

If the findings are not that important - either theoretically or practically - recommending rejection might make sense. However, we recommend taking the goals of the specific journal for which you are reviewing into consideration-a "one size fits all” approach is not advisable. For example, some journals pay more attention to theory building, others to the practical relevance of the findings, others like to publish replications, and so on.

How much weight should be placed on statistical/methodological errors or inconsistencies (such as unusual sample sizes, say $150<$ per cell, or $p=.15$ in a key study, or different and not well defended covariates in different studies)

It is important for authors to provide appropriate support for their theory. If you notice inconsistencies in reporting and/or use of statistical tests, it could be grounds for rejecting the paper. If the problems appear in one or two studies (but not all) and the paper meets your threshold for contribution, then you could point out the flaws to the authors and ask them to rectify these in the next round. However, if you notice intentional misreporting, then it may be best to indicate this in your confidential letter to the editor and let the associate editor and editor decide how to respond.

What are some considerations when an author uses a less widely preferred method (e.g., median split vs spotlight vs floodlight)?

We don't think using a method that is less widely used makes it less accurate or inappropriate. However, if these methods are avoided because they are flawed and/or other "better" methods are available, then you could certainly alert the authors to this possibility. Citing recent work that has used methods you consider more appropriate will be helpful for the authors. 
As a reviewer, what are some things to consider when bringing up a matter of preference?

As a reviewer, you could certainly indicate your preferences and highlight why you believe this approach is better. But, it is important for you to remember that the paper really belongs to the authors, and, if it is not something fundamental or something that affects readability, then it may be best left to the authors to use their discretion in using the approach they feel is best suited.

I just received a request from a non-regular outlet for me (e.g., a low-tier journal, a journal from outside the discipline). Should I bother to review it?

We think it is advisable to accept reviewing requests from all journals, particularly if you are a junior researcher. For one, it builds your reputation in the field and possibly even outside the field, which can be important for tenure decisions. As we mention in this field guide, it also helps keep you current regarding the literature. Finally, it is good to be a good citizen - you never know if one day you will want to submit to this journal.

I saw something in the paper that I think is incorrect (e.g., a calculation, the use of a method). Is it okay to ask a colleague about it?

It would be a disservice to the authors and to the journal if you saw something that was incorrect and didn't flag it. By all means ask a colleague-as long as you keep the paper itself confidential. Ask in a general way, without revealing the paper and the details. If you don't have anyone to confer with, raise this in private communication with the editor (Step 2: Recommendations to Editors, in this guide).

\section{What should you do if you receive a paper to review that you already have reviewed for another journal?}

Before accepting the review (or immediately upon noticing), tell the editor that you have reviewed this for a different journal. The editor will either recuse you and thank you, or ask that you nonetheless review this one, too. Sometimes, it is valuable for the editor to have the perspective of a reviewer who is very well suited to reviewing the work, even if she/he has previously reviewed it. 


\title{
Frequently Asked Questions about Responding to Reviews
}

\author{
After investing a lot of time and effort, people might start to have emotional attachment \\ with their papers. Therefore, any negative feedback received from a reviewer might be \\ perceived as a threat to self. For this type of situation, could you recommend any strategies \\ to clear authors of emotional attachment to their papers?
}

This is something that you will get used to over time. Try not to think of it as "negative" feedback; rather, try to reframe it for yourself as "constructive" feedback-feedback that will help your work ultimately make a difference. We address some of this in the section "How to Respond Effectively to Reviewers" of this field guide.

As an author, how does one handle disagreements with reviewers - and how does the response vary when the disagreement is over a more/less subjective matter?

If the disagreement is about something fundamental—such as the use of a theoretical framework or concerns about the empirical investigation, then it may be best to use the guidance provided by the associate editor in revising the paper for the next round. If, however, you strongly believe that your approach is appropriate, then you could stick with it, but do provide strong arguments indicating why you believe it is more appropriate. If the disagreement is merely one of preferences, then as an author it might just be easier to adhere to what the reviewers are asking, especially if there is consistency across reviewers in what they are asking you to do. We believe that, as an author, being open to the reviewers' guidance will not only help you navigate the review process more easily, but will also help you publish better papers.

\section{What do you do when reviewers disagree with one another?}

This is something that hopefully the associate editor and the editor have addressed when providing you with their reports. However, if they have not addressed inconsistencies explicitly, then you can choose the approach that you feel is best suited to address the spirit of the concern and indicate to the reviewers that this is how you have resolved the inconsistency. Clearly, it is important to be tactful in considering each reviewer's suggestions and explaining why their approach may not be the best suited to address the issue that they identified.

\section{When is it okay to write the editor to ask for clarifications?}

Always! If there is something unclear and/or inconsistent in the reviews, it is a good idea to get clarification from the editor before you spend a lot of time revising the manuscript. The editor might also confer with the associate editor, and then get back to you. Don't mistake clarification for permission. With rare exception (e.g., some journals invite authors to submit a revision plan), it is not okay to ask the editors for approval to take a certain path or run a particular study. While your plan may seem plausible on the surface, 
the devil is always in the details, and editors would not want to send an inappropriate signal of approval before the work has been evaluated by the full review team.

I don't think I can meet the deadline given to me by the editor for resubmission. Is it okay to ask for an extension?

Life happens. Of course, you may explain your circumstances and request an extension. Sometimes you need more time because you need to use a subject pool that doesn't open until after summer, or you only have permission to run a field study during off-peak store hours. If you have been as diligent as possible in working on your revision, editors understand that issues arise and will usually try to work with you.

The editor rejected my paper. Under what situations can I write back to the editor and request another opportunity? For instance, can I resubmit if I collect more data and believe I can fully address this issue?

This is tricky and every case is different. Generally speaking, when a paper is rejected you should seek publication in a different journal. However, sometimes the editor leaves on open door in the decision letter by inviting you to submit a new paper on the same topic. Typically the wording of this request will be something like "we would be happy to receive a new manuscript on this topic.” The key is the word "new." A resubmitted manuscript most likely requires new theorizing and almost entirely new empirical work. A good rule of thumb is that if it reads more as a revised manuscript, then a rejected paper should not be resubmitted to the same journal. If you really are unsure, you can ask a colleague for advice or even send the latest version to the editor and ask for an assessment regarding whether it can be resubmitted. 


\section{References}

Baker, Josephine Turck (1921), The Art of Conversation, Correct English Publishing Company.

Ballinger, Gary A. and Russell E. Johnson (2015), “Editors’ Comments: Your First AMR Review,” Academy of Management Review, 40 (3), 315-22.

Bernstein, Rachel (2015), “PLOS ONE ousts Reviewer, Editor after Sexist Peer-review Storm,” Science, downloaded at: http://www.sciencemag.org/news/2015/05/plos-one-oustsreviewer-editor-after-sexist-peer-review-storm.

Davis, Murray S. (1971), “That’s Interesting! Towards a Phenomenology of Sociology and a Sociology of Phenomenology,” Philosophy of the Social Sciences, 1 (4 Dec), 309-44.

Janiszewski, Chris, Aparna A. Labroo and Derek D. Rucker (2016), “Knowledge Creation and Knowledge Appreciation in Deductive-Conceptual Consumer Research,” Journal of Consumer Research.

Kohli, Ajay K. (2011), “From the Editor: Reflections on the Review Process,” Journal of Marketing, 75, 1-4.

Lynch, John G., Joseph W. Alba, Aradhna Krishna, Vicki Morwitz, and Zeynep Gurhan-Canli (2012), "Knowledge Creation in Consumer Research: Multiple Routes, Multiple Criteria," Journal of Consumer Psychology, 22: 473-85.

MacInnis, Debbie (2003), “Responsibilities of a Good Reviewer: Lessons Learned from Kindergarten,” Journal of the Academy of Marketing Science, 31 (3), 344-45.

Shugan, Steven M. (2007), “The Editor’s Secrets,” Marketing Science, 26 (5), 589-595. 
Sternberg, Robert J. (2006). Reviewing Scientific Works in Psychology, Washington, DC: American Psychological Association.

Summers, John O. (2001), “Guidelines for Conducting Research and Publishing in Marketing: From Conceptualization Through the Review Process," Journal of the Academy of Marketing Science, 29 (4), 401-15.

Stewart, David W. (2002), “Getting Published: Reflections of an Old Editor,” Journal of Marketing, 66 (October): 1-6.

Varadarajan, P. Rajan (1996), “From the Editor: Reflections on Research and Publishing,” Journal of Marketing, 60 (October), 3-6. 